\title{
Avaliação da produção de lipases por diferentes cepas de microrganismos isolados em efluentes de laticínios por fermentação submersa
}

\author{
Evaluation of lipase production using different strains of microorganisms \\ isolated from dairy effluent through submerged fermentation
}

Mirela ROVEDA ${ }^{1}$, Marcelo HEMKEMEIER ${ }^{1}$, Luciane Maria COLLA ${ }^{2 *}$

\section{Resumo}

A produção enzimática é um dos campos mais promissores dentro das tecnologias para a síntese de compostos de alto valor agregado, estando em constante crescimento pela grande capacidade dos microrganismos de realizarem transformações químicas. As enzimas produzidas por processos fermentativos têm sido utilizadas para o controle ambiental. Muitas destas enzimas podem ser produzidas a partir de resíduos industriais, diminuindo os custos de produção. As lipases são enzimas que catalisam a hidrólise de triglicerídeos em glicerídeos e ácidos graxos. As lipases vêm sendo utilizadas na redução da concentração dos lipídios contidos nos efluentes, promovendo a hidrólise dos óleos e gorduras presentes. Objetivou-se avaliar a produção de lipases por fungos isolados a partir de efluentes de laticínios. Foram isolados 21 fungos, pertencentes aos gêneros Penicillium, Aspergillus, Trichoderma e Fusarium. Na etapa de seleção, 9 fungos foram selecionados devido à capacidade de crescimento em meio contendo azeite de oliva como substrato. Na fermentação submersa, os fungos $\mathrm{E}_{9}$ (Aspergillus), $\mathrm{E}_{21}$ (Aspergillus) e $\mathrm{E}_{20}$ (Penicillium) foram os que apresentaram as maiores atividades enzimáticas, de 1,250 a 2,250 U, utilizando-se como meio de cultivo o efluente coletado na saída do equalizador do sistema de tratamento de efluente.

Palavras-chave: efluente de laticínios; fermentação submersa; lipases.

\begin{abstract}
Enzymatic production is one of the most promising fields within technologies for the synthesis of high added value compounds, given their constant growth due to the great capacity of microorganisms to carry out chemical transformations. The enzymes produced from fermentation processes have been used for environmental control. Many of these enzymes can be produced from industrial residues, reducing the production cost. Lipases are a group of enzymes that catalyze hydrolysis of triglycerides to glycerides and fatty acids. Lipases have been used to reduce the concentration of lipids contained in effluent, promoting hydrolysis of the oils and fats present. The aim of this work was to evaluate lipase production by fungi isolated from dairy effluent. We obtained 21 isolates of fungi, of the genus Penicillium, Aspergillus, Trichoderma and Fusarium. In the screening, nine isolates were selected on the basis of their capacity to grow in a medium containing olive oil as substrate. In submerged fermentation, the fungi $\mathrm{E}_{9}$ (Aspergillus), $\mathrm{E}_{21}$ (Aspergillus) and $\mathrm{E}_{20}$ (Penicillium) were the ones that presented the greatest enzymatic activity, from 1.250 to $2.250 \mathrm{U}$, using as cultivation medium the effluent collected from the treatment system equalizer.

Keywords: dairy effluent; submerged fermentation; lipases.
\end{abstract}

\section{Introdução}

A tecnologia enzimática é um dos campos mais promissores dentro das novas tecnologias para síntese de compostos de alto valor agregado (FERNANDES et al., 2004). A indústria química brasileira importa a maior parte das enzimas biocatalizadoras de matérias autossustentáveis (FERNANDES et al., 2004; LIMA et al., 2001). O interesse industrial por tecnologias enzimáticas vem aumentando gradativamente, especialmente nas áreas de engenharia de proteínas e enzimologia em meios não convencionais, as quais ampliaram consideravelmente o potencial de aplicação das enzimas como catalisadores em processos industriais. Entre os processos de maior interesse estão as reações de hidrólise, as de síntese e as de interesterificação de lipídios por meio das lipases (CASTRO et al., 2004). O elevado potencial de aplicação das lipases é justificado pela sua capacidade de utilização de uma ampla gama de substratos, sua estabilidade frente à temperatura, $\mathrm{pH}$ e solventes orgânicos, e sua régio e enantiosseletividade (FERNANDES et al., 2004). $\mathrm{O}$ reconhecimento dessas vantagens tem proporcionado um aumento considerável na produção e comercialização de lipases, resultando no desenvolvimento de tecnologias alternativas consistentes para utilização no setor industrial (CASTRO et al., 2004).

As lipases são amplamente encontradas na natureza, podendo ser obtidas a partir de fontes animais, vegetais e microbianas (CASTRO et al., 2004). Entretanto, somente as

Recebido para publicação em 26/2/2008

Aceito para publicação em 3/1/2009 (003258)

${ }^{1}$ Programa de Pós Graduação em Engenharia: Infraestrutura e Meio Ambiente, Faculdade de Engenharia e Arquitetura, Universidade de Passo Fundo - UPF, Campus I,

Km 171, BR 285, Bairro São José, CP 611, CEP 99001-970, Passo Fundo - RS, Brasil, E-mail: marceloh@upf.br

2 Curso de Engenharia de Alimentos, Faculdade de Engenharia e Arquitetura, Universidade de Passo Fundo - UPF, Passo Fundo - RS, Campus I, Km 171, BR 285,

Bairro São José, CP 611, CEP 99001-970, Passo Fundo - RS, Brasil, E-mail: Imcolla@upf.br

${ }^{*}$ A quem a correspondência deve ser enviada 
lipases microbianas são comercialmente utilizadas. As lipases microbianas constituem um importante grupo de enzimas, devido à versatilidade de suas propriedades e à fácil produção em massa. As lipases microbianas são amplamente diversificadas em suas propriedades enzimáticas e especificidade do substrato, o que as torna muito atrativas para a aplicação industrial (HASAN; SHAH; HAMMED, 2006).

Os fungos filamentosos são considerados bons produtores de enzimas (MAIA et al., 2001), e as lipases fúngicas são as preferidas para aplicação industrial (MAHADIK et al., 2002).

As lipases (triacilglicerol-acil hidrolases, EC 3.1.1.3) catalisam a hidrólise e a síntese de triacilgliceróis (ésteres de glicerol e ácidos graxos de cadeia longa). As muitas aplicações das lipases incluem sínteses orgânicas, hidrólise e modificação de gorduras e óleos, realce do sabor no processamento de alimentos, definição de misturas racêmicas e análises químicas (SHARMA; CHISTI; BANERJEE, 2005). Novas aplicações vêm se estabelecendo nos mais diversos campos, tais como indústrias farmacêuticas, químicas, cosméticas, na oleoquímica, nas indústrias de couros, polpa de celulose e papel e no tratamento de resíduos industriais (CASTRO et al., 2004).

As enzimas de origem microbiana possuem muitas vantagens sobre as equivalentes de origem animal ou vegetal, como o menor custo de produção, a possibilidade de produção em larga escala em fermentadores industriais, além de oferecer um amplo espectro de características físico-químicas. A diversidade de microrganismos existentes justifica a busca por novos produtores de enzimas (CARVALHO et al., 2005; LIMA et al., 2001). A identificação de novas fontes microbianas, principalmente não tóxicas ao organismo humano, é de interesse estratégico, pois, além de garantir o suprimento de enzimas aos mais variados processos industriais, tornam possível o desenvolvimento de novos sistemas enzimáticos que não podem ser realizados a partir de enzimas vegetais ou animais (OLIVEIRA et al., 2006).

As enzimas podem ser indutivas, ou seja, produzidas pelos microrganismos na presença de um indutor, que pode ser o próprio substrato ou o produto da sua hidrólise, o qual pode ser adicionado ao meio de cultivo a fim de estimular a produção.

A utilização de enzimas no tratamento de efluentes industriais tem sido desenvolvida como alternativa ao tratamento convencional e tem despertado grande interesse para a pesquisa, em função das vantagens apresentadas. A utilização do efluente para a produção de lipases é um processo viável e de baixo custo, visto que este apresenta uma elevada carga de nutrientes ainda disponíveis para o crescimento fúngico e a posterior produção de enzimas.

Objetivou-se isolar e selecionar fungos produtores de lipases a partir de efluentes de laticínios e produzir lipases via fermentação submersa, utilizando os fungos selecionados e o próprio efluente como meio de cultivo.

\section{Material e métodos}

\subsection{Coleta do efluente}

O efluente de laticínios foi coletado na saída do equalizador e do aerador de um sistema de tratamento de efluentes da Região de Passo Fundo. Os pontos foram escolhidos pela diferença de concentração de óleos e gorduras entre eles. O equalizador consiste em um equipamento com a função de homogeneizar a vazão e a carga do efluente, sendo utilizado para solucionar problemas operacionais causados pela variação de fluxo, melhorando a performance dos sistemas subsequentes e reduzindo custo e tamanho do sistema de tratamento (METCALFE; EDDY, 1993). A saída do equalizador caracterizase por grande concentração de óleos e gorduras, enquanto na saída do tanque de aeração a concentração de óleos de gorduras é menor devido ao efluente já ter sofrido várias etapas do tratamento. O efluente coletado foi utilizado para o isolamento dos microrganismos (item 2.2) e como meio de cultivo para a produção de lipases (item 2.4).

\subsection{Isolamento e identificação dos fungos}

O isolamento dos microrganismos foi realizado através da semeadura direta do efluente em meio ABD (ágar batata dextrose - Acumedia) acidificado com ácido tartárico 10\%. Em placas de Petri contendo o meio ABD, foram inoculados $0,3 \mathrm{~mL}$ de amostra de efluente, realizando-se o espalhamento com uma alça de Drigalsky. As placas foram incubadas a $30{ }^{\circ} \mathrm{C}$ durante 5 dias. A sequência do isolamento foi realizada através da técnica de esgotamento por estrias. Os microrganismos isolados foram mantidos em tubos de ensaio contendo o meio $\mathrm{ABD}$ a $4{ }^{\circ} \mathrm{C}$. Os fungos isolados foram identificados quanto ao gênero através da realização de microcultivos (RIBEIRO; SOARES, 2001).

\subsection{Seleção de fungos produtores de lipases}

Os fungos isolados na etapa anterior (item 2.2) foram testados quanto à habilidade de crescimento em meio $\mathrm{ABD}$ adicionado de $5 \%$ de azeite de oliva.

A inoculação foi realizada pontualmente no centro das placas de Petri contendo o meio de cultivo. A partir de uma suspensão de esporos em ágar $0,1 \%$, foi realizada a inoculação pontual no centro da placa contendo o meio. Os cultivos foram mantidos em estufa a $30^{\circ} \mathrm{C}$ por 144 horas.

O crescimento dos fungos foi avaliado a partir da medida dos raios a cada 24 horas através do uso de um paquímetro. Os experimentos foram realizados em triplicata. A velocidade de crescimento radial foi calculada através da regressão linear dos dados de raio das colônias versus tempo, segundo a Equação 1.

$$
\begin{aligned}
& r(\mathrm{~cm})=V C R . t+b \\
& \mathrm{r}(\mathrm{cm})=\text { raio; } \\
& \mathrm{t}=\text { tempo }(\mathrm{dia}) ; \\
& \mathrm{VCR}=\text { velocidade de crescimento radial ( } \mathrm{cm} / \mathrm{dia}) ; \mathrm{e} \\
& \mathrm{b}=\text { coeficiente linear da regressão. }
\end{aligned}
$$


Os dados de VCR dos fungos foram analisados através de Anova e Teste de Tukey para comparação de médias.

\subsection{Produção de lipases via fermentação submersa}

\section{Microrganismos}

Os fungos selecionados no item 2.3 foram utilizados para a produção de lipases via fermentação submersa.

\section{Preparo do inóculo}

O preparo dos inóculos foi realizado em placas de Petri contendo o meio $\mathrm{ABD}$ (Acumedia) utilizando os fungos que apresentaram maiores velocidades de crescimento radial. $\mathrm{O}$ inóculo foi incubado durante 7 dias em estufa a $30^{\circ} \mathrm{C}$. Após o crescimento, foi preparada uma suspensão de esporos através da adição de $20 \mathrm{~mL}$ de uma solução de $0,1 \%$ de emulsificante Tween 80 (Synth), seguida de raspagem dos esporos com uma alça de Drigalsky e filtração em gaze estéril para retenção das hifas. A inoculação dos meios foi realizada adicionando-se $5 \mathrm{~mL}$ de solução de esporos para cada $200 \mathrm{~mL}$ de meio de cultivo.

\section{Meio de cultivo e condições experimentais}

O meio de cultivo utilizado nas fermentações foi o efluente de laticínios coletado nas saídas do equalizador e do aerador, ao qual se adicionaram os seguintes nutrientes: $0,1 \%$ de nitrato de sódio $\left(\mathrm{NaNO}_{3}\right), 0,1 \%$ de fosfato de potássio monobásico $\left(\mathrm{KH}_{2} \mathrm{PO}_{4}\right), 0,05 \%$ de sulfato de magnésio $\left(\mathrm{MgSO}_{4} .7 \mathrm{H}_{2} \mathrm{O}\right)$ e $1 \%$ de azeite de oliva como indutor. $\mathrm{O}$ pH foi ajustado a $6,5 \mathrm{com}$ $\mathrm{H}_{2} \mathrm{SO}_{4} 1,5 \mathrm{M}$.

Os experimentos foram realizados em duplicata em Erlenmeyers de $500 \mathrm{~mL}$, com volume inicial de meio de $200 \mathrm{~mL}$, e mantidos em agitador orbital a $30^{\circ} \mathrm{C}$ por 4 dias, com agitação de $130 \mathrm{~min}^{-1}$. Amostras de $10 \mathrm{~mL}$ foram coletadas no tempo inicial e a cada 24 horas, para determinação da atividade lipolítica.

\section{Determinação da atividade lipolítica}

A atividade lipolítica foi determinada através do método descrito por Burkert, Maugeri e Rodrigues (2004), que é baseado na titulação com $\mathrm{NaOH} 0,05$ mol.L-1 dos ácidos graxos liberados pela ação da enzima lipase presente no extrato enzimático da fermentação, sobre os triacilglicerídeos do óleo de oliva emulsionados em goma arábica. $\mathrm{O}$ meio de fermentação foi filtrado para retenção das hifas e o extrato obtido, utilizado para a determinação da atividade enzimática. Em frascos de $125 \mathrm{~mL}$, foram adicionados $2 \mathrm{~mL}$ de tampão fosfato $10 \mathrm{mmol} . \mathrm{L}^{-1} \mathrm{com} \mathrm{pH}$ 7,0 e $5 \mathrm{~mL}$ de emulsão de azeite de oliva (75\% de solução de goma arábica 7 e $25 \%$ de azeite de oliva). A este sistema foi adicionado $1 \mathrm{~mL}$ de extrato enzimático da fermentação e incubado a $37^{\circ} \mathrm{C}$ por 30 minutos a $160 \mathrm{~min}^{-1}$. Após a incubação, a reação foi paralisada pela adição de $15 \mathrm{~mL}$ de solução acetona:etanol:água 1:1:1 v/v e os ácido graxos liberados titulados com uma solução de $\mathrm{NaOH}$ 0,05 mol. $\mathrm{L}^{-1}$, utilizando fenolftaleína como indicador. Uma unidade de atividade enzimática (U) foi definida como a quantidade de enzima necessária para liberar $1 \mu_{\text {mol }}$ de ácido graxo por minuto por $\mathrm{mL}$ de meio fermentado, nas condições do ensaio. As determinações de atividade lipolítica foram realizadas em duplicata.

A produtividade enzimática máxima foi calculada através da Equação 2:

$P_{E}=\frac{A E_{\max }-A E_{t 0}}{t_{f}}$

$\mathrm{P}_{\mathrm{E}}=$ produtividade enzimática máxima;

$\mathrm{AE}_{\text {max }}=$ atividade enzimática máxima;

$\mathrm{AE}_{\mathrm{t} 0}=$ atividade enzimática inicial; $\mathrm{e}$

$t_{f}=$ tempo de fermentação em que foi observada a atividade máxima.

\section{Resultados e discussão}

\subsection{Isolamento e seleção dos fungos}

Foram isolados 21 fungos a partir do efluente de laticínios utilizado (denominados fungos $\mathrm{E}_{1}$ a $\mathrm{E}_{21}$ ). A realização dos microcultivos possibilitou identificar os fungos isolados através da análise microscópica dos micélios. Os fungos $\mathrm{E}_{6}, \mathrm{E}_{7}, \mathrm{E}_{8}, \mathrm{E}_{9}, \mathrm{E}_{10}$, $\mathrm{E}_{15}, \mathrm{E}_{17}$ e $\mathrm{E}_{21}$ foram identificados como do gênero Aspergillus; os fungos $\mathrm{E}_{3}, \mathrm{E}_{12}, \mathrm{E}_{20}$, como Penicillium; os fungos $\mathrm{E}_{2}, \mathrm{E}_{13}, \mathrm{E}_{18}, \mathrm{E}_{19}$, como Trichoderma; os fungos $\mathrm{E}_{1}, \mathrm{E}_{4}, \mathrm{E}_{5}, \mathrm{E}_{14}$, como Fusarium; $\mathrm{e}$ o fungo $\mathrm{E}_{16}$ não foi identificado.

\subsection{Seleção de fungos produtores de lipases}

A Tabela 1 apresenta as velocidades de crescimento radial para os fungos isolados do efluente de laticínios, cultivados em ABD com a adição de $5 \%$ de azeite de oliva.

A velocidade de crescimento radial (VCR) é o coeficiente angular da reta obtida a partir da regressão linear dos raios das colônias em função do tempo, portanto, quanto maior a inclinação da reta, maior é a velocidade de crescimento radial, maior o potencial de crescimento do fungo e o potencial de degradação da fonte de carbono adicionada (azeite de oliva).

As VCRs dos fungos isolados do efluente de laticínios foram analisadas através da Anova, sendo observadas diferenças significativas entre os resultados obtidos pelos diferentes fungos ( $\mathrm{p}<0,001)$. A comparação das médias de VCR dos fungos através do Teste de Tukey demonstrou que os fungos $\mathrm{E}_{6}, \mathrm{E}_{17}, \mathrm{E}_{10}$, $\mathrm{E}_{21}, \mathrm{E}_{8}, \mathrm{E}_{9}, \mathrm{E}_{7}, \mathrm{E}_{20}$ e $\mathrm{E}_{12}$ apresentaram VCRs significativamente superiores $(\mathrm{p}<0,05)$ às dos demais fungos, sendo utilizados para a continuidade dos experimentos de fermentação submersa.

As elevadas velocidades de crescimento radial apresentadas pelos fungos $\mathrm{E}_{6}, \mathrm{E}_{7}, \mathrm{E}_{8}, \mathrm{E}_{9}, \mathrm{E}_{10}, \mathrm{E}_{12}, \mathrm{E}_{17}, \mathrm{E}_{20}$ e $\mathrm{E}_{21}$ indicam a habilidade destes fungos de crescerem em meios contendo azeite de oliva como fonte de carbono. Estes fungos são pertencentes aos gêneros Aspergillus e Penicillium.

Sharma, Chisti e Banerjee (2001) citam inúmeras cepas de fungos como boas produtoras de lipases, entre elas Aspergillus, Rhizopus, Penicillium, Mucor, Geotrichum, 
Tabela 1. Velocidade de crescimento radial (VCR) dos fungos isolados de efluente de laticínios, cultivados em Ágar Batata Dextrose com a adição de 5\% de azeite de oliva.

\begin{tabular}{ccc}
\hline Fungo & Gênero & $\mathrm{VCR}^{1,2}(\mathrm{~cm} / \mathrm{d})$ \\
\hline $\mathrm{E}_{6}$ & Aspergillus & $1,774 \pm 0,004^{\mathrm{a}}$ \\
$\mathrm{E}_{17}$ & Aspergillus & $1,681 \pm 0,018^{\mathrm{ab}}$ \\
$\mathrm{E}_{10}$ & Aspergillus & $1,663 \pm 0,032^{\mathrm{ab}}$ \\
$\mathrm{E}_{21}$ & Aspergillus & $1,553 \pm 0,034^{\mathrm{abc}}$ \\
$\mathrm{E}_{8}$ & Aspergillus & $1,530 \pm 0,042^{\mathrm{abc}}$ \\
$\mathrm{E}_{9}$ & Aspergillus & $1,425 \pm 0,148^{\mathrm{bcd}}$ \\
$\mathrm{E}_{7}$ & Aspergillus & $1,367 \pm 0,006^{\mathrm{cd}}$ \\
$\mathrm{E}_{20}$ & Penicillium & $1,344 \pm 0,038^{\mathrm{cd}}$ \\
$\mathrm{E}_{12}$ & Penicillium & $1,160 \pm 0,000^{\mathrm{d}}$ \\
$\mathrm{E}_{16}$ & - & $0,684 \pm 0,002^{\mathrm{e}}$ \\
$\mathrm{E}_{14}$ & Fusarium & $0,653 \pm 0,054^{\mathrm{e}}$ \\
$\mathrm{E}_{18}$ & Trichoderma & $0,639 \pm 0,222^{\mathrm{ef}}$ \\
$\mathrm{E}_{1}$ & Fusarium & $0,486 \pm 0,050^{\mathrm{efg}}$ \\
$\mathrm{E}_{13}$ & Trichoderma & $0,386 \pm 0,024^{\mathrm{efgh}}$ \\
$\mathrm{E}_{19}$ & Trichoderma & $0,395 \pm 0,012^{\mathrm{fghi}}$ \\
$\mathrm{E}_{5}$ & Fusarium & $0,297 \pm 0,000^{\mathrm{ghij}}$ \\
$\mathrm{E}_{11}$ & Levedura & $0,166 \pm 0,088^{\mathrm{hijl}}$ \\
$\mathrm{E}_{15}$ & Aspergillus & $0,104 \pm 0,026^{\mathrm{jm}}$ \\
$\mathrm{E}_{3}$ & Penicillium & $0,080 \pm 0,015^{\mathrm{lm}}$ \\
\hline
\end{tabular}

${ }^{1}$ Resultados de média \pm desvio padrão; $\mathrm{e}^{2}$ médias seguidas de letras diferentes indicam diferença significativa $(\mathrm{p}<0,05)$.

Fusarium, Rhizomucor, Acremonium e Alternaria. Segundo Carvalho et al. (2005); Hasan, Shah e Hammed (2006); Mendes e Castro (2005), os fungos do gênero Aspergillus e Penicillium são bons produtores de lipase. Na literatura não foram encontrados relatos da produção de lipases por cepas de Trichoderma. Os fungos do gênero Fusarium têm se mostrado bons produtores, entre estes a cepa de Fusarium solani, como demonstrado por Maia et al. (2001).

A seleção de cepas selvagens superprodutoras ainda é uma técnica de grande importância, principalmente em países que apresentam uma grande biodiversidade como o Brasil (VARGAS, 2004), o que justifica a busca de fontes alternativas de novas cepas fúngicas para a produção de lipases.

\subsection{Atividade lipolítica}

A Tabela 2 apresenta as atividades lipolíticas máximas (U) e as produtividades máximas (U/d) obtidas através de fermentação submersa de efluente como meio de cultivo, utilizando os fungos selecionados no item 2.3.

Verifica-se na Tabela 2 que as maiores atividades lipolíticas foram obtidas utilizando-se o efluente coletado na saída do equalizador como meio de cultivo para a produção de lipases.

As atividades lipolíticas máximas foram obtidas utilizandose como meio de cultivo o efluente coletado na saída do equalizador, a partir dos fungos $\mathrm{E}_{9}, \mathrm{E}_{20} \mathrm{e} \mathrm{E}_{21}$, de 1,250 U, 2,042 U e 2,250 U, respectivamente (Tabela 2). Entretanto, verifica-se
Tabela 2. Máximas atividades lipolíticas e produtividades obtidas via fermentação submersa utilizando como meio de cultivo os efluentes coletados na saída do equalizador e na saída do tanque de aeração de uma indústria de laticínios.

\begin{tabular}{lcccc}
\hline Fungo & $\begin{array}{c}\text { Ponto de coleta } \\
\text { do efluente }\end{array}$ & $\begin{array}{c}\text { Atividade } \\
\text { lipolítica } \\
\text { máxima (U) }\end{array}$ & $\begin{array}{c}\text { Tempo } \\
\text { máximo de } \\
\text { produção }(\mathrm{d})\end{array}$ & $\begin{array}{c}\text { Produtividade } \\
\text { máxima }^{*} \\
(\mathrm{U} / \mathrm{d})\end{array}$ \\
\hline E-6 & Saída do & 0,496 & 1 & 0,068 \\
E-7 & $\begin{array}{c}\text { equalizador } \\
\text { P3*1 }\end{array}$ & 0,579 & 1 & 0,151 \\
E-8 & 0,744 & 1 & 0,316 \\
E-9 & & 1,250 & 2 & 0,411 \\
E-10 & & 0,750 & 4 & 0,081 \\
E-12 & & - & - & - \\
E-17 & & 0,667 & 1 & 0,239 \\
E-20 & & 2,042 & 2 & 0,807 \\
E-21 & & 2,250 & 4 & 0,456 \\
E-6 & Saída do & 0,597 & 1 & 0,321 \\
E-7 & aerador & - & - & - \\
E-8 & P6 ${ }^{* 2}$ & - & - & - \\
E-9 & & - & - & - \\
E-10 & & 0,500 & 2 & 0,121 \\
E-12 & & 0,417 & 1 & 0,159 \\
E-17 & & 0,333 & 2 & 0,038 \\
E-20 & & 0,333 & 1 & 0,075 \\
E-21 & & - & - & - \\
\hline
\end{tabular}

${ }^{* 1} \mathrm{AE}$ inicial $=0,428(\mathrm{U}) ;{ }^{* 2} \mathrm{AE}$ inicial $=0,258(\mathrm{U}) ;{ }^{* 3} P E=\frac{A E \max -A E t 0}{t f}$.

que para os fungos $\mathrm{E}_{9}$ e $\mathrm{E}_{20}$, a atividade máxima foi obtida em 2 dias de fermentação, enquanto que para o fungo $E_{21}$, a atividade máxima foi obtida no tempo de 4 dias. Desta forma, a produtividade máxima em lipases, de 0,807 U/dia, foi obtida com o fungo $\mathrm{E}_{20}$, em 2 dias de fermentação.

$\mathrm{O}$ fungo $\mathrm{E}_{20}$ foi classificado como do gênero Penicillium, enquanto que os fungos $\mathrm{E}_{9}$ e $\mathrm{E}_{21}$ foram pertencentes ao gênero Aspergillus, sendo ambos reportados como bons produtores de lipases por Carvalho et al. (2005), Hasan, Shah e Hammed (2006), Mendes e Castro (2005).

A partir de fungos cultivados em efluente da produção de óleos, foram obtidas atividades lipolíticas superiores a 0,30 UI.mL $\mathrm{mL}^{-1}$. As atividades lipolíticas mais elevadas foram obtidas com C. cylindracea NRRL Y-17506 e G. candidum Y-553 do C. $\left(0,46\right.$ e 0,52 UI. $\mathrm{mL}^{-1}$, respectivamente) após 168 horas de fermentação. Os autores definiram 1 UI como a quantidade de enzima que produz $1 \mu \mathrm{mol}$ produto/minuto nas condições do ensaio, tendo sido utilizado o método espectrofotométrico que usa $\beta$-naftilmiristato como substrato (D'ANNIBALLE et al., 2005).

A determinação das melhores condições requeridas para a produção de lipases pelo $A$. cinnamomea em culturas submersas em frascos agitados foi realizada por Lin, Wang e Sung (2005). Uma vez que a composição do meio afeta a produção de lipases drasticamente, é importante compreender a influência de vários fatores para determinar as condições ótimas de cultivo. Estes autores empregaram diferentes fontes 
de nitrogênio, em concentração de $0,5 \%(\mathrm{p} / \mathrm{v})$, para a produção de lipases em culturas submersas de A. cinnamomea. As fontes estudadas foram amônia, sais de amônio, proteínas, peptídeos e aminoácidos. A produção máxima de lipases foi de 6,41 mU.mL $\mathrm{m}^{-1}$ para a cultura suplementada com L-aspargina, seguida pela glicina $\left(5,36 \mathrm{mU} \cdot \mathrm{mL}^{-1}\right)$, triptona $\left(4,77 \mathrm{mU} \cdot \mathrm{mL}^{-1}\right)$ e L-glutamina $\left(4,74 \mathrm{mU} \cdot \mathrm{mL}^{-1}\right)$. Em nosso estudo, a fonte de nitrogênio utilizada foi o nitrato de sódio.

Vários autores, como Mahadik et al. (2002) e Baron, Turra e Krieger (2005), utilizaram o azeite de oliva como indutor da produção de lipases, o que está de acordo com o utilizado neste trabalho. Entretanto, o custo da adição de azeite de oliva como indutor é elevado se for considerada a produção de enzimas em larga escala. Desta forma, pode-se estudar a utilização de outros indutores, como o óleo de soja proveniente de frituras, o qual seria facilmente obtido, visto ser um resíduo de restaurantes e da indústria. Segundo Carvalho et al. (2005), os valores da atividade enzimática na hidrólise do azeite de oliva têm sido amplamente utilizados para efeito de comparação e seleção de cepas produtoras de lipases. Estes valores podem variar significativamente dependendo do tipo de fermentação, da composição do meio de cultivo e também de outras variáveis do processo fermentativo, tais como $\mathrm{pH}$, temperatura de incubação e presença de indutores da síntese de lipases, como os óleos vegetais.

A produção de lipases por Penicillium corylophilum IOC 4211 foi estudada por Baron, Turra e Krieger (2005) em dois meios de cultivo. O primeiro continha $0,2 \% \mathrm{KNO}_{3} ; 0,1 \%$ $\mathrm{K}_{2} \mathrm{HPO}_{4} ; 0,05 \% \mathrm{MgSO}_{4} .7 \mathrm{H}_{2} \mathrm{O} ; 0,043 \% \mathrm{ZnSO}_{4} .7 \mathrm{H}_{2} \mathrm{O} ; 0,11 \%$ $\mathrm{FeSO}_{4} \cdot 7 \mathrm{H}_{2} \mathrm{O} ; 0,015 \% \mathrm{MnSO}_{4} .4 \mathrm{H}_{2} \mathrm{O} ; 1,25 \%\left(\mathrm{NH}_{4}\right)_{2} \mathrm{SO}_{4} ; 0,5 \%$ de extrato de levedura; $2 \%$ de peptona de carne; e $1 \%$ de óleo de oliva. Já o segundo meio de cultivo continha $0,14 \%$ de $\mathrm{NH}_{4} \mathrm{NO}_{3}$; $0,073 \% \mathrm{MgSO}_{4} .7 \mathrm{H}_{2} \mathrm{O} ; 0,067 \% \mathrm{KH}_{2} \mathrm{PO}_{4} ; 0,01 \% \mathrm{ZnSO}_{4} .7 \mathrm{H}_{2} \mathrm{O}$; $0,0007 \% \mathrm{FeSO}_{4} \cdot 7 \mathrm{H}_{2} 0 ; 0,067 \%$ de glicose; e $2 \%$ de óleo de oliva. As atividades enzimáticas obtidas com o segundo meio de cultivo foram superiores, de 7,1 U.mL ${ }^{-1}$ após 6 dias de fermentação a $29^{\circ} \mathrm{C}$ e $120 \mathrm{~min}^{-1}$. Já com o primeiro meio de cultivo, o qual era mais simples, obteve-se atividade máxima de $3,25 \mathrm{U}_{\mathrm{mL}} \mathrm{m}^{-1}$ após 3 dias de fermentação. Os meios de cultivo utilizados pelos autores são meios com maior quantidade de nutrientes que o meio de cultivo utilizado para a produção de lipases em nosso trabalho, que utilizou o efluente de laticínios adicionado de nutrientes (nitrato de sódio, fosfato de potássio monobásico, sulfato de magnésio e azeite de oliva), o que justifica as menores atividades enzimáticas obtidas. $\mathrm{O}$ meio de cultivo utilizado neste trabalho consiste em um meio barato, visto ser um efluente. Novas pesquisas podem ser realizadas a fim de otimizar a produção de lipases pelos fungos selecionados, estudando-se a adição de outros nutrientes ao efluente, temperaturas de produção, $\mathrm{pH}$, concentração de oxigênio dissolvido, entre outros.

O melhor meio de cultivo para a produção de lipases foi o efluente da saída do equalizador (P3). A concentração de óleos e gorduras nas saídas do equalizador e do aerador foi de 1,89 mg. $\mathrm{L}^{-1} \pm 0,38 \mathrm{mg} . \mathrm{L}^{-1}$ e 1,81 mg.L. $\mathrm{L}^{-1} \pm 0,67 \mathrm{mg} . \mathrm{L}^{-1}$ de óleos e gorduras, respectivamente, não havendo diferença significativa entre estes valores $(\mathrm{p}=0,9185)$. Desta forma, a maior produção de lipases no efluente da saída do equalizador não pode ser justificada pela concentração de óleos e gorduras, visto que ambos os efluentes possuíam quantidades similares de óleos e gorduras. Entretanto, o efluente coletado na saída do equalizador apresentou maiores quantidades de matéria orgânica (DQO $\left.835,97 \pm 17,26 \mathrm{mg} \cdot \mathrm{L}^{-1}\right)$ e fósforo $\left(0,26 \pm 0,04 \mathrm{mg} \cdot \mathrm{L}^{-1}\right)$, em comparação com o efluente coletado na saída do aerador (DQO 115,90 $\pm 61,37 \mathrm{mg} . \mathrm{L}^{-1}$ e fósforo 0,06 \pm 0,01 mg. $\mathrm{L}^{-1}$ ). O nitrogênio é um nutriente essencial para a formação estrutural dos fungos, bem como para a produção de enzimas, visto estas serem constituídas de aminoácidos, que apresentam nitrogênio na sua estrutura.

\section{Conclusões}

Na etapa de isolamento de microrganismos, foram isolados 21 fungos pertencentes aos gêneros Aspergillus, Penicillium, Fusarium e Trichoderma, dos quais 9 (Aspergillus e Penicillium) foram selecionados devido à capacidade de crescimento em meio contendo azeite de oliva. Na fermentação submersa, os fungos pertencentes aos gêneros Aspergillus (E-9 e E-21) e Penicillium (E-20) apresentaram as maiores atividades enzimáticas de 1,250, 2,042 e 2,250 U. A maior produção de lipases ocorreu com a utilização do efluente da saída do equalizador. O uso do próprio efluente na produção de lipases constitui uma alternativa para a diminuição dos custos de produção desta enzima, aliado ao fato do aproveitamento do efluente. A produção de lipases, que utiliza o efluente é viável, uma vez que esta apresenta elevada carga de nutrientes ainda disponíveis para o crescimento fúngico e produção de enzimas. A presença de lipídios no efluente possibilita a produção das lipases, uma vez que estes são utilizados como fonte de carbono para o crescimento fúngico. Além disso, as lipases produzidas podem ser utilizadas posteriormente no tratamento de efluentes.

\section{Referências bibliográficas}

BARON, A. M.; TURRA, V.; KRIEGER, N. Produção e caracterização de lipases de Penicillium corylophilum IOC 4211. In: SIMPÓSIO NACIONAL DE FERMENTAÇÕES, 15., 2005, Recife. Anais...

BURKERT, J. F. M.; MAUGERI, F.; RODRIGUES, M. I. Optimization of extracellular lipase production by Geotrichum sp. using factorial design. Bioresource Technology, v. 91, n. 1, p. 77-84, 2004.

CARVAlHO, P. O. et al. Potencial de biocatálise enantiosseletiva de lipases microbianas. Química Nova, v. 28, n. 4, p. 614-621, 2005.

CASTRO, H. F. et al. Modificação de óleos e gorduras por biotransformação. Química Nova, v. 27, n. 1, p. 146-156, 2004.

D'ANNIBALE, A. et al. Olive-mill wastewaters: a promising substrate for microbial lipase production. Bioresource Technology, v. 97, n. 15, p. 1828-1833, 2005.

FERNANDES, M. L. M. et al. Hydrolysis and synthesis reactions catalysed by Thermomyces lanuginosa lipase in AOT/Isooctane reversed micellar system. Journal of Molecular Catalysis B: Enzymatic, v. 30, p. 43-49, 2004.

HASAN, F.; SHAH, A. A.; HAMMED, A. Industrial application of microbial lipases. Enzyme and Microbial Technology, v. 39, n. 2, p. 235-251, 2006.

LIMA, V. M. G. M. Produçăo e purificaçăo da lipase de Bacillus megaterium CCOC-P2637 e sua aplicaçăo em biocatálise em 
solventes orgânicos. Curitiba, 2004. 148 p. Tese (Doutorado em Bioquímica) - Universidade Federal do Paraná - UFPR.

LIN, E. S.; WANG, C. C.; SUNG, S. C. Cultivating conditions influence lipase production by the edible Basidiomycete Antrodia cinnamomea in submerged culture. Enzyme and Microbial Technology, v. 39, n. 1, p. 98-102, 2005.

MAHADIK, N. D. et al. Production of acidic lipase by Aspergillus niger in solid state fermentation. Process Biochemistry, v. 38, n. 5, p. 715-721, 2002.

MAIA, M. M. D. et al. Effect of culture conditions on lipase production by Fusarium solani in batch fermentation. Bioresource Technology, v. 76, n. 1, p. 23-27, 2001.

MENDES, A. A.; CASTRO, H. F. Aplicação de lipases no tratamento de águas residuárias com elevados teores de lipídeos. Química Nova, v. 28 , n. 2, p. 296-305, 2005.
METCALF \& EDDY. Wastewater Engineering: treatment, disposal and reuse. 3 ed. New York: McGraw-Hill, 1993. 1334 p.

OLIVEIRA, A. N. et al. Enzimas hidrolíticas extracelulares de isolados de Rizóbia nativos da Amazônia Central, Amazonas, Brasil. Ciência e Tecnologia de Alimentos, v. 26, n. 4, p. 853-860, 2006.

RIBEIRO, M. C.; SOARES, M. M. Microbiologia prática: roteiro e manual, bactérias e fungos. 1 ed. Rio de Janeiro: Atheneu, 2001. $112 \mathrm{p}$.

SHARMA, R.; CHISTI, Y.; BANERJEE, Y. C. Production, purification, characterization and applications of lipases. Biotechnology Advances, v. 19, n. 8, p. 627-662, 2005.

VARGAS, G. D. L. P. Estudo da produção de lipase por Penicillium simplicissimum utilizando torta de soja como substrato. Erechim, 2004, 106 p. Dissertação (Mestrado em Engenharia de Alimentos) Universidade Regional Integrada - URI. 